\title{
Intensity effects of cortical polarization during consolidation
}

\author{
STEPHEN D. BERRY and CHARLES W. SNYDER \\ University of Notre Dame, Notre Dame, Indiana 46556
}

\begin{abstract}
Thirty-six male, albino rats were tested daily on a one-way shuttle avoidance task. Immediately after each session, anodal and cathodal polarization groups were given $1 \mathrm{~h}$ of cortical polarization of the appropriate polarity at either 23.9 or $47.8 \mu \mathrm{A} / \mathrm{mm}^{2}$ current density. Control animals received no current. Significant differences in number of avoidances were found between the anodal and control groups at each current level and between cathodal and control groups at the lower polarization level. Differences in the effectiveness of different levels of polarization suggested that the upper effective limit of current was approached at $47.8 \mu \mathrm{A} / \mathrm{mm}^{2}$, and that the optimal level of polarization might be lower for cathodal than for anodal current. The results were discussed in terms of the role of extracellular dc fields in learning and memory, with emphasis on delineating the optimal limits of applied polarization.
\end{abstract}

Cortical extracellular direct current (dc) fields have been implicated in the neurophysiological processes underlying learning. Rowland (1968) has reviewed the pertinent literature and cited the potential role of applied dc current (polarization) studies in clarifying the significance of these phenomena in learning. Early polarization experiments concentrated on molecular aspects of behavior such as electromyographic changes or single-unit responses to external stimulation during polarization and after its cessation (Morrell, 1961; Rusinov, 1963). These studies showed the significance of dc fields in the formation of temporary connections at the cortical level. On a molar behavioral level, Albert (1966a, 1966b) has shown that cathodal polarization can prevent the interhemispheric transfer of avoidance learning, and anodal polarization can restart consolidation prevented by $\mathrm{KCl}$ spreading depression. Cathodal polarization has been shown to disrupt aversively motivated tasks such as leg flexion (Morrell \& Naitoh, 1962) and one-way avoidance (Berry, Sim, \& Snyder, 1969), as well as appetitive tasks (e.g., visual discrimination reversal: Kupferman, 1965). Anodal polarization, on the other hand, has been shown to facilitate learning. Stamm and Rosen (1972) demonstrated that polarization of prefrontal cortex in monkeys facilitated the acquisition of delayed response learning. This effect, they noted, seems to be stronger on the day following polarization. Thus, applied dc tields can alter the rate of behavioral learning, specifically affecting the rate at which experiences are consolidated into long-term memory.

S. D. Berry is now at the University of California at Irvine. Address reprint requests to S. D. Berry, Department of Psychobiology, Steinhaus Hall, University of California, Irvine, California 92717.
The strength of the polarizing current, within certain limits, would logically seem to be an important variable. The lower effective limit would be the point below which the dc field exerts no tonic influence on cells in the polarized area. The upper limit should be below the current strength at which tissue damage results. Studies showing no effects on acquisition (Kupferman, 1965) or a weak effect (Berry et al., 1969) have used relatively low current levels (10 and $7.9 \mu \mathrm{A} / \mathrm{mm}^{2}$, respectively). In contrast, Stamm and Rosen (1972) achieved their best results using higher current levels (up to $20 \mu \mathrm{A} / \mathrm{mm}^{2}$ ). The present experiment attempts to evaluate the effects of high levels of polarization on the acquisition of a simple avoidance task. The characteristics of the stimulator and cortical electrodes used here yielded current levels of 23.9 or $47.8 \mu \mathrm{A} / \mathrm{mm}^{2}$ of either anodal or cathodal polarization.

\section{METHODS}

\section{Subjects}

Thirty-six naive, male albino rats (Holtzman), 90-120 days of age and weighing 280-390 g, were randomly assigned to six groups: anodal, 23.9; cathodal, 23.9; control, 23.9; anodal, 47.8; cathodal, 47.8; and control, 47.8 .

\section{Surgery}

The members of each group were anesthetized with sodium pentobarbital (Nembutal) and implanted with bilateral cortical electrodes. The electrodes were constructed of stainless steel wire and plastic cannulae $(1.0 \mathrm{~mm}$ i.d.) and fixed to the skull with dental acrylic and stainless steel screws. Each cannula was filled with a saline-soaked cotton wick, which was to rest on the cortical surface. Coordinates were $3.5 \mathrm{~mm}$ posterior to bregma and $2.5 \mathrm{~mm}$ to either side of the midline, with the skull level. A stainless steel wire was implanted subcutaneously in the back of each rat to complete the polarization circuit. The postoperative recovery period was 5 days. 


\section{Apparatus}

The apparatus was a one-way shuttlebox, $137 \times 15.2 \times 17.8 \mathrm{~cm}$ high. The startbox was a white-walled, grid-floored chamber (61 $\mathrm{cm}$ long), separated by a guillotine door from the black-walled goalbox, $76 \mathrm{~cm}$ in length. A variable autotransformer provided footshock current through a $20 \mathrm{~K} \Omega$ resistor and grid scrambler. A microswitch mounted under the solid floor of the goalbox terminated the cycle of a timer set to record latencies to the nearest $.01 \mathrm{sec}$. Polarizing current was supplied by a Heathkit IP-32 regulated power supply which, through a resistor circuit, provided 23.9 or $47.8 \mu \mathrm{A} / \mathrm{mm}^{2}$ of anodal or cathodal current at the cortical electrodes. Two timers and a capacitor-resistor charge/discharge circuit produced a continuous recycling of a unidirectional pulsating current. The pulsations of current were used to minimize the damaging effects of dc voltage across brain tissue. The cycle was as follows: $15 \mathrm{sec}$ smooth increase from 0 to maximum current, $45 \mathrm{sec}$ of steady current, $15 \mathrm{sec}$ decrease to 0 , and $45 \mathrm{sec}$ of no current.

\section{Procedure}

Immediately following the recovery period, the testing sessions began. The rat was placed in the start chamber of the shuttlebox, starting an automatic timer. After $5.0 \mathrm{sec}$, the footshock was given at a level of $2.5 \mathrm{~mA}$ if the animal was still in the startbox. Both the shock and a latency timer were terminated when the rat entered the goalbox. Each session consisted of a recall test and an acquisition trial. The intertrial interval was on a VI 30-sec schedule, with intervals ranging from 15 to $45 \mathrm{sec}$.

After each session, the rat was returned to a special holding chamber and immediately given $1 \mathrm{~h}$ of slowly pulsating polarizing current. Animals in the anodal groups had the anode of the dc field connected to the bilateral cortical electrodes, with the cathode located at the wire implanted in the back. For the cathodal groups, the wire leads were switched, reversing the polarity of polarization. The control groups were placed in the holding chambers and connected to dummy leads, controlling for any variable except polarizing current. Each subject underwent five sessions at 24-h intervals, receiving polarization immediately after each session. Since the polarizing stimulator could not supply current at both levels simultaneously, the 23.9- and $47.8-\mu \mathrm{A} / \mathrm{mm}^{2}$ groups of each polarity were run at different times on the same days. For this reason, two separate control groups were run, but the control scores were combined for data analysis.

Following the final day's testing, all animals were sacrificed with an overdose of pentobarbital. The chronic implant and some surrounding bone were removed, and the dorsal surface of the brain was inspected for infection and/or incidental surgical damage. Any infected rat, or any rat receiving worse than a slight cortical depression under an electrode, was discarded from the study.

\section{RESULTS}

The data recorded were the latencies between the start of the test trial and the performance of the appropriate escape or avoidance response. Any latency below $5.0 \mathrm{sec}$ indicated an avoidance response, and the number of avoidances was noted. Table 1 shows the number of animals in each group exhibiting an avoidance response in each of the four retention tests. Note that the $\mathbf{N}$ in the combined control group is twice that of any other treatment, so that these scores would be halved to maintain proportion with the other groups.

Mann-Whitney $U$ tests between polarization groups were performed on the total number of avoid- ances across days for each rat. Both anodal groups (A and $\mathrm{C}$ in Table 1) showed significantly more avoidances than control Group $E(U=14, p=.05$, and $U=15, p=.05$, respectively), but $A$ was better than $\mathrm{C}(\mathrm{U}=7, \mathrm{p}=.047)$. While cathodal Group B was worse than control $(U=16, p=.05)$, $D$ was not significantly different from control $(U=28$, not significant). B was, however, significantly worse than $\mathrm{D}(\mathrm{U}=7, \mathrm{p}=.047)$. The differences between anodal and cathodal polarization groups at each current level was in the predicted direction (anodal learning faster than cathodal). Although highly significant at $23.9 \mu \mathrm{A} / \mathrm{mm}^{2}$ (Group A vs. Group B: $\mathrm{U}=5, \mathrm{p}=.02)$, the difference at $47.8 \mu \mathrm{A} / \mathrm{mm}^{2}$ failed to reach statistical significance $(U=8, p=$ .066 , Group C vs. Group D).

Significant differences were also found in the effects of different levels of the same current polarity. Lower levels of anodal polarization produced faster learning (Group A vs. Group C, $U=7, p=.047$ ), while lower levels of cathodal polarization produced significantly fewer avoidances (Group B vs. Group D, $\mathrm{U}=7, \mathrm{p}=.047)$. However, it should be noted that, while both anodal groups perform significantly better than controls, only one cathodal group (B) was significantly affected by the treatments.

\section{DISCUSSION}

These results indicate that anodal polarization has a significant facilitatory effect on the acquisition of an avoidance response, but that the magnitude of this effect begins to decrease as current levels approach $47.8 \mu \mathrm{A} / \mathrm{mm}^{2}$. Similarly, cathodal polarization significantly retards the rate of acquisition, but, in this polarity, higher levels of current eliminate the effectiveness of the treatment altogether. The effects reported here appear rather strong upon closer examination of the data. The majority of each anodal group avoided shock consistently on and after the third retention test, the control group on the 4th day, and one cathodal group (B) apparently did not learn (although one animal in this group learned a consistent avoidance response).

Table 1

Number of Avoidance Responses Shown by the Members of Each Experimental Group During the Four Retention Tests

\begin{tabular}{|c|c|c|c|c|c|c|c|}
\hline \multirow[b]{2}{*}{ Group } & \multirow[b]{2}{*}{ Treatment } & \multirow[b]{2}{*}{$\mathbf{N}$} & \multicolumn{4}{|c|}{ Retention Test } & \multirow[b]{2}{*}{ Total } \\
\hline & & & 1 & 2 & 3 & 4 & \\
\hline A & $23.9 \mathrm{uA} / \mathrm{mm}^{2}$ Anodal & 6 & 2 & 2 & 4 & 4 & 12 \\
\hline B & $23.9 \mathrm{uA} / \mathrm{mm}^{2}$ Cathodal & 6 & 0 & 2 & 2 & 1 & 5 \\
\hline $\mathrm{C}$ & $47.8 \mathrm{uA} / \mathrm{mm}^{2}$ Anodal & 6 & 0 & 2 & 5 & 4 & 11 \\
\hline D & $47.8 \mathrm{uA} / \mathrm{mm}^{2}$ Cathodal & 6 & 1 & 1 & 3 & 4 & 9 \\
\hline $\mathrm{E}$ & Control & 12 & 2 & 2 & 5 & 8 & 17 \\
\hline
\end{tabular}

Note-there are twice as many rats in the combined control group $(E)$. 
These results suggest, for two reasons, that the strength of polarization is an important parameter in effects on learning. First, the data obtained following $23.9 \mu \mathrm{A} / \mathrm{mm}^{2}$ of current show stronger effects than those following lower current levels in other studies, especially those in our own laboratory using $7.9 \mu \mathrm{A} / \mathrm{mm}^{2}$ (Berry et al., 1969). Secondly, $47.8 \mu \mathrm{A} /$ $\mathrm{mm}^{2}$ appears to be above the optimal level of polarization, since anodal polarization at this level produces a weaker effect than at lower levels, and cathodal current, which has strong effects at lower levels, shows no effect on performance at this level.

Stamm and Rosen (1972) showed an effect of anodal polarization on a difficult appetitive task, with current applied during the actual performance of the task. Our findings extend the facilitative effects of anodal polarization to simple, aversively motivated tasks, and also show that polarization can be effective if given immediately after, rather than during, the learning trials.

Previous data on rats and closely related species (e.g., rabbits) have shown clearly only the effects of cathodal polarization on overt behavior (Berry et al., 1969; Kupferman, 1965; Morrell \& Naitoh, 1962). The present results with anodal polarization would appear to be a better illustration of the effects of dc fields, since, in the case of cathodal current, nonspecific factors (e.g., injury to tissue) must be shown not to be the causative agent in learning deficit (see Rowland, 1968, p. 57).

The attenuation of cathodal impairment of learning at higher levels suggest that the optimal level of cathodal polarization may be lower than that for anodal current. This is supported by the fact that studies using lower current levels (e.g., Berry et al., 1969) tend to show effects of cathodal, but not anodal, polarization. At the same time, studies which show quite dramatic cathodal alterations in learning (e.g., Stamm \& Rosen, 1972) have used intermediate (approximately $20 \mu \mathrm{A} / \mathrm{mm}^{2}$ ) levels such as the lower current used in the present study.

At this point, it is still highly speculative to extrapolate these findings to the endogenous physiological situation. Slow extracellular potentials have been recorded and correlated with various of the phenomena which accompany a learning task. Endogenous dc shifts have been shown to correlate with cognitive events such as expectancy (e.g., the CNV, see Walter, Cooper, Aldridge, McCallum, \& Winter, 1964). Others have correlated dc shifts more with events such as activation or arousal (Rowland, 1967). Still others (Pinto-Hamuy, Bracchitta, \& Lagarrigue, 1969) report that these dc shifts do not correlate with emotional activation or alertness, but relate more closely to associative aspects of the learning itself. Polarization studies do not support any of these hypotheses to the exclusion of the others. They do, however, support the role of extracellular dc fields in learning phenomena, and can help elucidate this role in terms of the optimal strength and polarity of such fields. In the future, when the action of dc fields is better understood, smaller, more localized polarization fields may help outline the functions of various brain regions during learning. The present experiment, as well as those cited above, suggests the important influences of extracellular fields at the cortical level during learning and consolidation, and begins to delineate the upper and lower effective limits of applied dc fields.

\section{REFERENCES}

AlberT, D. J. The effect of spreading depression on the consolidation of learning. Neuropsychologia, 1966, 4, 49-64. (a)

AlberT, D. J. The effects of polarizing currents on the consolidation of learning. Neuropsychologia, 1966, 4, 65-76. (b)

BerRY, S. D., SIM, D. G., \& SNYDER, C. W. Cortical polarization effects on consolidation of avoidance learning in rats. Psychonomic Science, 1969, 16, 20-21.

KuPFERMAN, I. Effects of cortical polarization on visual discriminations. Experimental Neurology, 1965, 12, 179-189.

MorRELL, F. Effect of anodal polarization on the firing pattern of single cortical cells. Annals of the New York Academy of Sciences, 1961, 92, 860-876.

MorRell, F., \& NaItoh, P. Effect of cortical polarization on a conditioned avoidance response. Experimental Neurology, 1962, 6, 507-523.

Pinto-Hamuy, T., Bracchitta, H., \& Lagarrigue, I. Slow cortical potentials (SCP) during habituation, conditioning and extinction in rabbit cortex. Neuropsychologia, 1969, 7, 335-347.

Rowland, V. Steady potential phenomena of cortex. In G. C. Quarton, T. Melnechuk, \& F. O. Schmitt (Eds.), The neurosciences: $A$ study program. New York: Rockefeller University Press, 1967.

Rowland, V. Cortical steady potential (direct current potentials) in reinforcement and learning. In E. Stellar \& J. M. Sprague (Eds.), Progress in physiological psychology. New York: Academic Press, 1968.

Rusinov, V. S. An electrophysiological analysis of the connecting function on the cerebral cortex in the presence of a dominant region area. Abstract Communications of the XIX International Physiology Congress, Montreal, 1953. Pp. 719-720.

Stamm, J. S., \& Rosen, S. C. Cortical steady potential shifts and anodal polarization during delayed response performance. Acta Neurobiologiae Experimentalis, 1972, 32, 193-209.

W alter, W. G., Cooper, R., Aldridge, V. S., McCallum, W. C., \& Winter, A. L. Contingent negative variation: An electric sign of sensorimotor association and expectancy in the human brain. Nature, 1964, 203, 380-384.

(Received for publication September 27, 1977; revision accepted February 2, 1978.) 